\title{
A REPRESENTAÇÃO FICCIONAL EM DOIS ROMANCES DE BERNARDO CARVALHO
}

\author{
Gisele Novaes Frighetto*
}

\begin{abstract}
Resumo
Este artigo propõe analisar a representação ficcional em dois romances de Bernardo Carvalho, Nove noites (2002) e $O$ Sol se põe em São Paulo (2007), de forma a perceber como neles são problematizadas a linguagem literária e a construção da narrativa. Além disso, relacionaremos os aspectos analisados com as resenhas e crônicas do autor publicadas em $O$ mundo fora dos eixos (2005) e com textos de Barthes (2004) e Foucault (1990 e 2009), para delinear uma proposta literária na qual o texto ocupe o primeiro plano e enrede o leitor em relatos complementares ou contraditórios, numa narrativa aberta à ambiguidade.
\end{abstract}

\section{Palavras-chave}

Bernardo Carvalho, Nove Noites, O Sol se Põe em São Paulo, representação ficcional, linguagem literária.

\begin{abstract}
This article aims at analysing the fictional representation in Bernardo Carvalho's two novels, Nove Noites (2002) e $O$ Sol se põe em São Paulo (2007), in order to realize how there literary language and the construction of narrative are problematized. Furthermore, the analysed aspects will be related to reviews and chronicles of the author, collected in $O$ mundo fora dos eixos (2005), besides studies carried out by Barthes (2004) and Foucault (1990 and 2009). It will be attempted to show a literary proposal where the text occupies the first place and involves the reader into contradictory or complementary stories, in a narrative open to ambiguity.
\end{abstract}

\section{Keywords}

Bernardo Carvalho, Nove Noites, O Sol se Põe em São Paulo, fictional representation, literary language.

* Doutoranda no Programa de Pós-Graduação em Teoria Literária e Literatura Comparada na FFLCH - USP. Bolsista da Coordenação de Aperfeiçoamento de Pessoal de Nível Superior (Capes).E-mail: giselefrighetto@uol.com.br. 


\section{Introdução}

ove noites, romance publicado em 2002, parte de um evento
histórico, a morte do antropólogo Buell Quain entre os índios Krahô
em 1939. A trama acompanha a investigação de um jornalista anônimo, que se interessa pela história por conta da leitura de uma notícia de jornal. $\mathrm{O}$ enredo é composto nos deslocamentos desse personagem em busca de pistas, pelas cartas de Buell Quain e pelos relatos de pessoas que o conheceram ou ouviram falar dele.

O título alude ao tempo passado entre Quain e Manoel Perna, personagem ficcional cujos relatos, "encontrados" pelo narrador em sua viagem à Carolina a aos Krahô, é entremeado a fotografias e cartas retiradas de arquivos. As cartas são escritas ou dirigidas a personagens históricos como Ruth Benedict, Heloísa Alberto Torres, Albert Métraux ou Bernard Mishkin, entretanto, as fontes nem sempre são confiáveis e algumas vezes imprecisas.

Por fim, podem ser levantadas hipóteses sobre a razão do suicídio - o contato com a barbárie, a fascinação pelo suicídio, o conflito com a homossexualidade, o desajuste ou a angústia da existência, um amor fracassado e um filho ilegítimo -, mas não há resposta. E a única morte que se pode conhecer é aquela que acontece no desfecho da narrativa, quando o narrador tenta dormir nem que seja "só para calar os mortos" (CARVALHO, 2006, p.150).

O Sol se põe em São Paulo, de 2007, é um romance construído em torno de versões da história de Michiyo, narrativa que transcorreria no Japão e no Brasil, nos anos 1940 e 1950. Michiyo inventa uma identidade falsa (Setsuko) para contar sua história a um aspirante a escritor anônimo e inicialmente narra um triângulo amoroso entre ela, Jokichi e Masukichi. O desfecho trágico e a natureza desse conflito são alterados ao longo da narrativa, na medida em que são descortinados novos relatos. Assim, de forma semelhante a Nove Noites, a trama inicial entremeia-se a outros relatos e faz parte de um enredo maior, protagonizado por um narrador-escritor em busca.

Bernardo Carvalho tematiza nos dois romances a própria ficção e seu caráter de impostura e fingimento, ou seja, problematiza a natureza e as possibilidades da representação ficcional e da linguagem literária, por meio da exploração de relatos incompletos ou contraditórios e do emprego de pontos de vista subjetivos e múltiplos. Além dos romances em questão, os textos críticos reunidos em $O$ mundo fora dos eixos (2005) são esclarecedores da proposta literária do escritor, na qual o texto como linguagem ocupa o primeiro plano e são desafiados os limites da representação. 


\section{A linguagem como objeto}

Ambos os romances são construídos por narradores em primeira pessoa que buscam reconstituir um evento passado, sem atingir plenamente seu objetivo. As narrativas são compostas por cartas e relatos deixados pelos personagens, o que faz com que outros narradores se expressem e os enredos sejam fragmentados. Tanto SPSP como $N N^{1}$ são compostos por uma espécie de narrativa moldura, na qual um narrador aspirante a escritor/jornalista busca revelar a trama central, que aparece em trechos narrativos complementares ou contraditórios, sem que haja uma versão definitiva dos acontecimentos. Os narradores são enredados, como os leitores, em tramas que não se dão a desvendar completamente, ao sabor de lembranças das personagens a respeito dos eventos e de diferentes interpretações dos fatos ocorridos, o que acaba por causar descontinuidades na condução da trama e também uma reflexão sobre o ofício de narrar.

Os primeiros períodos do romance SPSP deixam clara a indefinição que o romance trará ao leitor. "Não vejo nenhuma metáfora no que eu digo. É como se tudo estivesse na sombra" (CARVALHO, 2007, p. 9). Isso também ocorre em $N N$, que se inicia com as cartas de Manoel Perna, engenheiro que convivera com Quain durante sua estadia entre os indígenas, as quais intermediarão a narrativa das descobertas do narrador jornalista.

Vão lhe dizer muitas coisas. Sei o que espera de mim. E o que deve estar pensando. Mas não me peça o que nunca me deram, o preto no branco, a hora certa. Terá que contar apenas com o imponderável e a precariedade do que agora lhe conto [...] (CARVALHO, 2006, p. 7)

Manoel Perna provoca o destinatário de suas cartas - também desconhecido e saudado com "isto é para quando você vier", o que de certa forma alude ao papel do leitor na narrativa - ao afirmar, mais de uma vez, a respeito dos encontros com Quain, que "Agora o que lhe conto é a combinação do que ele me contou e da minha imaginação ao longo de nove noites" (CARVALHO, 2006, p. 41).

Podemos afirmar que o que interessa nessas narrativas não é propriamente o que é narrado, mas como é narrado. A arte ficcional ou a urdidura de um enredo tornam-se mais importantes do que o acontecimento. Em uma concepção autônoma de literatura, sua interpretação advém exclusivamente da relação entre leitor e texto e da construção particular de sentido. O narrador de $N N$ afirma esse papel atribuído ao texto literário ao dizer que "Cada um lê os poemas como pode e neles entende o que quer, aplica o sentido dos versos à sua própria experiência acumulada até o momento em que os lê" (CARVALHO, 2006, p. 102).

Bernardo Carvalho tematiza nesses romances os limites da representação ficcional e da construção dos sentidos, fazendo com que o texto literário tenha por tema o próprio texto. Nesse sentido, O Sol se põe em São Paulo é claramente metaficcional e

\footnotetext{
1 Os romances serão referenciados como SPSP (O Sol se põe em São Paulo) e NN (Nove noites).
} 
redefine em muitos momentos o papel da literatura e do escritor. Em Nove Noites, esse projeto aparece diluído na exploração dos sentidos do texto e da experiência narrada.

Nas palavras de Michiyo, personagem de SPSP, "A literatura não é o que se vê. A literatura engana" (CARVALHO, 2007, p. 31). Aqui, o texto não é feito do relato de experiências vividas como o quer Walter Benjamin, e sim, esvaziada a sua unidade e seu sentido, do entremeado de discursos que nada mais são do que linguagem. Vazio de experiência, o narrador não pode compor uma narrativa exemplar, mas reconstruir precariamente o mundo do outro.

Esses aspectos vêm ao encontro das propostas enunciadas por Bernardo Carvalho em $O$ mundo fora dos eixos. Um deles parece ser o de que o texto literário não deve enfatizar significados facilmente apreensíveis ou ser mera representação do mundo cognoscível e da subjetividade. Em Teatro do indizível, Carvalho considera que a obra literária é, sobretudo, texto, no qual sobressai a disposição de seus significantes e suas sugestões, em detrimento de uma linguagem que seja ilusoriamente e meramente referencial: "Régy tenta mostrar que o teatro, assim como o texto literário que está na sua base, não é simples comunicação. $O$ que procura exprimir não é da ordem da clareza, mas do incompreensível" (CARVALHO, 2005, p. 43).

Dessa forma, o escritor deve explorar os sentidos do texto em suas possibilidades de mistério e incerteza. Na resenha sobre o que chama Teatro do nocaute, tematiza uma crise da referencialidade da linguagem ou a representação de um real inominável. O interessante é deixar as palavras boiarem a deriva de seus significados, "uma espécie de quarto escuro da linguagem". "Para socar as coisas com as palavras até elas perderem os sentidos, levando o mundo a nocaute, a esse estado sem opinião e sem regras em que por fim é possível encarar um outro sentido (não viciado) das coisas" (CARVALHO, 2005, p. 189).

Essa concepção de texto e de linguagem pode ser relacionada a textos importantes para uma concepção autônoma da literatura e do texto, bem como de uma liberação do discurso frente às coerções que o vinculariam a critérios de aceitabilidade, dentre eles o de verdade ou referencialidade.

Em As palavras e as coisas, Foucault (1990) propõe uma arqueologia do pensamento sistemático ou científico de ordenação do mundo por meio da linguagem. Propõe o desvanecimento da convergência entre representação e linguagem na modernidade (séc. XIX), o que faz com que a literatura somente manifeste o reaparecimento do ser vivo da linguagem, deslocando-se da função representativa ou significante da linguagem para o ser da linguagem, enquanto objeto de interpretação ou composição.

Em vez de uma correlação entre palavras e coisas dada por uma lógica natural ou pela ênfase no caráter representativo da linguagem, Foucault propõe o olhar sobre o incompreensível, zona mediana que compõe o modo do mundo e que resiste ao domínio do discurso. Admitir a existência desse espaço variável significa verificar o quê a linguagem não consegue aderir, e cujo significado fica em suspenso nos enunciados. 
De tal sorte que essa região "mediana", na medida em que manifesta os modos de ser da ordem, pode apresentar-se como a mais fundamental: anterior às palavras, às percepções e aos gestos, incumbidos então de traduzi-la com maior ou menor exatidão ou sucesso [...]; mais sólida, mais arcaica, menos duvidosa, sempre mais "verdadeira" que as teorias que lhes tentam dar uma forma explícita, uma explicação exaustiva, ou um fundamento filosófico. (FOUCAULT, 1990, p. 11)

A resistência do mundo e do cerne de um indivíduo à linguagem faz com que seus significados tenham muito de inconcluso, de imaginativo. Em Nove Noites, Manoel Perna avisa “[...] pois o segredo, sendo o único bem que se leva para o túmulo, é também a única herança que se deixa aos que ficam, como você e eu, à espera de um sentido [...]" (CARVALHO, 2006, p. 6).

O leitor de Carvalho é assim impelido a assumir o real da linguagem, não do mundo, e a criar sentidos intercambiáveis ou variáveis. Isso faz com que em suas obras opere-se o movimento anunciado por Barthes (2004b), Da obra ao texto, considerandose objetos de análise o texto e a linguagem de que é feito. Desvinculado da biografia do escritor ou da realidade circundante, o texto prova-se com relação ao signo e pratica o recuo do significado. O seu campo é do significante, encarado não em sua ligação indissociável ao significado, mas como um jogo que obedece a movimentos de desligamento e variação. O texto é, pois, radicalmente simbólico: “[...] uma obra de que se concebe, percebe e recebe a natureza radicalmente simbólica é um texto" (BARTHES, 2004b, p. 69).

Foucault (2009) também alerta que a literatura deve ser pensada não a partir de uma teoria da significação, mas de compreensão dos movimentos de sua linguagem. Essa concepção se relaciona a outra proposta do autor, enunciada em $A$ ordem do discurso, de compreender as coerções que impedem o discurso de ser enunciado, validado e, também, compreendido na sua descontinuidade e heterogeneidade.

Essa concepção afasta o texto literário de obra única, ao perceber como dela e de qualquer artefato de linguagem fazem parte a fragmentação e a relação com outros textos. Esse aspecto é ressaltado por Barthes (2004a) em A morte do autor, ao afirmar que um texto não tem sentido único, mas é espaço onde se casam e se contestam escrituras variadas, dentre as quais nenhuma é original. O texto é, pois, um "tecido de citações, oriundas dos mil focos de cultura" (p. 62).

Tecidos de citações, os romances são compostos pelas vozes dos relatos dos personagens e inspirados nas vozes de autores canônicos como Junichiro Tanizaki, em O Sol se põe em São Paulo, e Joseph Conrad, em Nove Noites. Essas citações enredam o leitor num jogo de referências que esclareceriam ilusoriamente a trama romanesca, evidenciando o caráter intertextual explícito das narrativas literárias contemporâneas.

Diante da morte do autor, Barthes propõe o nascimento do leitor: ele é o responsável por reunir essa escritura múltipla e deslindar seus sentidos, ambiguidades e perceber os vários discursos que nela se entrecruzam. "[...] o leitor é o espaço onde se inscrevem, sem que nenhuma se perca, todas as citações de que é feita uma escritura; a unidade do texto não está em sua origem, mas no seu destino" (BARTHES, 2004a, p. 64). 
A personagem Michiyo, de SPSP, enreda o narrador (e, por conseguinte, o leitor) ao mesmo tempo em que chama a atenção para o fato de que tudo não passa de linguagem e, sendo romance, de uma mentira bem contada. "Vou repetir. Tente me acompanhar, caro Masukichi, e verá que tudo sempre esteve debaixo dos nossos olhos e ao nosso alcance. Fomos nós que não quisemos ver" (CARVALHO, 2007, p. 150-151).

Para Barthes (2004b), o único autor que nos interessa é aquele que está inscrito no texto, já que "[...] também o eu que escreve nunca é mais do que um eu de papel” (p. 72). E, tais como os narradores escritores anônimos, os leitores vários são impelidos a decifrarem a narrativa que não cessa de se reconstruir, sem se encerrar. $O$ ato de ler torna-se acontecimento; já que o leitor e o próprio texto, afinal, "[...] todo texto é escrito eternamente aqui e agora" (BARTHES, 2004a, p. 61).

Nos romances, ainda, os narradores, jornalistas ou escritores que buscam construir uma história a partir de documentos $(N N)$, viagens e vivências (ambos os romances) despertam no leitor a suspeita de ser o próprio Bernardo Carvalho, transmudado em alter ego ou autoficção.

Jamais será possível saber, pela simples razão que a escritura é a destruição de toda voz, de toda origem. A escritura é esse neutro, esse composto, esse oblíquo pelo qual foge o nosso sujeito, o branco-e-preto que vem se perder toda identidade, a começar pela do corpo que escreve. (BARTHES, 2004a, p. 57)

A epígrafe de Paul Valéry em SPSP, “[...] estranhos discursos, que parecem feitos por um personagem distinto daquele que os diz e dirigir-se a outro, distinto daquele que os escuta", alude ao caráter outro daquele que conta, tornado linguagem e aquele que lê, transfigurado por ela. Escritor e leitor são, pois, feitos de linguagem, assim como as personagens, cuja "morte" se dá com o fim da escritura.

Em Nove Noites, a morte de Quain aconteceria ao final da narração, quando o narrador desiste de encontrar uma resposta, metaforizada pela história sobre os Nazca, que cortariam as línguas dos mortos para que não atormentassem os vivos. Em $O$ Sol se põe em São Paulo, a visita ao monte Koya, “[...] onde os mortos permanecem vivos” (p. 115) também é emblemática, já que os personagens da trama romanesca, naquele momento provavelmente todos mortos, revivem pela escritura.

Entretanto, além das pistas autorreferenciais, os romances nos deixam entrever as convicções do Bernardo Carvalho, publicadas em seus textos críticos. Nesse sentido, podemos estabelecer um diálogo com Foucault (2009), que embora trace a figura do autor como princípio de rarefação do discurso, percebe-o como ligado a uma exterioridade na qual repousa a influência, mesmo que tênue, do escritor. $\mathrm{O}$ autor é concebido como princípio de agrupamento do discurso, como unidade e origem de suas significações, como foco de sua coerência. Foucault relativiza essa noção ao afirmar que um autor é aquele que escreve uma obra possível num horizonte de discursos, a qual será construída por leituras a posteriori. 
Pois embora possa modificar a imagem tradicional que se faz de um autor, será a partir de uma nova posição do autor que recortará, em tudo o que poderia ser dito, em tudo o que diz todos os dias, a todo momento, o perfil ainda trêmulo de sua obra. (FOUCAULT, 2009, p. 29)

Em Impasse da consciência, Carvalho elogia a busca de uma linguagem literária que fosse a expressão do desconhecido, essência do homem e da vida humana, com suas descontinuidades, paradoxos e contradições, ocultos pela linguagem corrente. "O desconhecido só poderia ser concebido por uma linguagem que é posta em jogo" (CARVALHO, 2005, p. 213).

A literatura, sendo movimento sem fim, desejo e busca permanentes (mais errância, crise e interrogação do que resposta), seria capaz de chamar o desconhecido sem ter que nomeá-lo, e assim tocá-lo de alguma forma sem cair no paradoxo de torná-lo conhecido, refém das convenções da linguagem [...].

(CARVALHO, 2005, p. 213)

Essa literatura, que se afasta de um real de sentidos plenos e de compreensibilidade, demandaria leitores mais engajados. Para Beal (2005), a descontinuidade do enredo, a indefinição entre real e ficcional e a necessidade de reflexão sobre a natureza da narrativa literária filiaria a narrativa de Carvalho a uma tradição de escritores que se iniciaria com Machado de Assis. Entretanto, enquanto Machado privilegiaria a linguagem dentro de um "real ficcional", Bernardo Carvalho apagaria as distinções entre ficção e realidade.

Machado's reader must make the leap that language is what comprises the novel, its true subject; Carvalho's reader must go a step further, pulling reality into the realm of fiction, to say that language comprises us. Machado thus privileges language, but only within the realm of fiction, whereas Carvalho breaks down the distinction between fiction and reality. We are our stories, even when these stories are "real."

$\left(\right.$ BEAL, 2005, p. 136) ${ }^{2}$

A imaginação parece ter papel fundamental na literatura de Bernardo Carvalho. Em seus escritos críticos, opõe uma "arte da invenção", calcada na criação, a uma "arte da imitação", incorporada por uma arte da reprodução. Essa primeira arte desafiaria o leitor e chamaria sua atenção para a constituição da compreensão de uma "linguagem que seja algo em si antes de significar alguma coisa" (CARVALHO, 2005, p. 102).

2 Tradução minha: O leitor de Machado deve perceber que a linguagem é o que compõe o romance e é o seu verdadeiro assunto. O leitor de Carvalho deve dar um passo adiante, e encarar a realidade como o cerne da ficção, para dizer que somos compostos de linguagem. Machado também privilegia a linguagem, mas dentro da ficção, enquanto que Carvalho rompe com a distinção entre ficção e realidade. Nós somos nossas histórias, mesmo que essas histórias sejam "reais". 


\section{O real ficcional}

Em Nove Noites, o ponto de partida do enredo é a descoberta do suicídio de Buell Quain em uma nota de jornal, o que ancora o romance em uma espécie de realidade documental. Nos agradecimentos, vemos como dados obtidos e fontes do narrador coincidem com as pesquisas realizadas pelo autor, que adverte: "Este é um livro de ficção, embora esteja baseado em fatos, experiências e pessoas reais" (CARVALHO, 2006, p. 151).

Carvalho parece desafiar a pretensa veracidade dos documentos nos quais se baseia a historiografia, já que os relatos das cartas são, também, pontos de vista sobre os acontecimentos. Há, no romance, referências a documentos endereçados ou escritos por antropólogos e pesquisadores da época, mas deve-se ressaltar que as fontes de informações partem muitas vezes de cartas do próprio Quain e de relatos nos quais o narrador deduz uma referência ao antropólogo, como o relato de Bernard Mishkin a Albert Métraux sobre a homossexualidade do investigado. "Métraux não se conteve em suas notas: 'Como caluniador, não há ninguém melhor do que Mishkin'” (CARVALHO, 2006, p. 116).

Em $O$ desejo de quem conta, Carvalho (2005) relativiza o imperativo de verdade dos relatos, encarados como representação de mundo. É importante que a representação seja pensada, em vez de apagada em nome do que é dito. Essa representação é uma sedução, um jogo entre quem conta e quem ouve, e o relato é resultado do "desejo de quem fala" e da sua capacidade de despertar no ouvinte "o desejo de ouvir e acreditar": "A narrativa da experiência passada (real ou não) é a criação do desejo, no presente" (CARVALHO, 2005, p. 151).

As fotografias de Buell Quain e de antropólogos no Museu Nacional também ancoram ilusoriamente o romance no real. Entretanto, se encararmos as fotografias como imagens que falam por si, tal como sugere Carvalho (2005) em suas crônicas, podemos perceber como a figura da fotografia do rosto de Quain, embora retirada do acervo da casa de Cultura Heloísa Alberto Torres (IPHAN), não se limita a representar a figura de um suicida, mas também possibilita hipóteses sobre sua personalidade, já que a fotografia sugere, na sua expressão, sentidos como desafio ou altivez.

Fotografia de Buell Quain. (CARVALHO, 2006, p. 23)
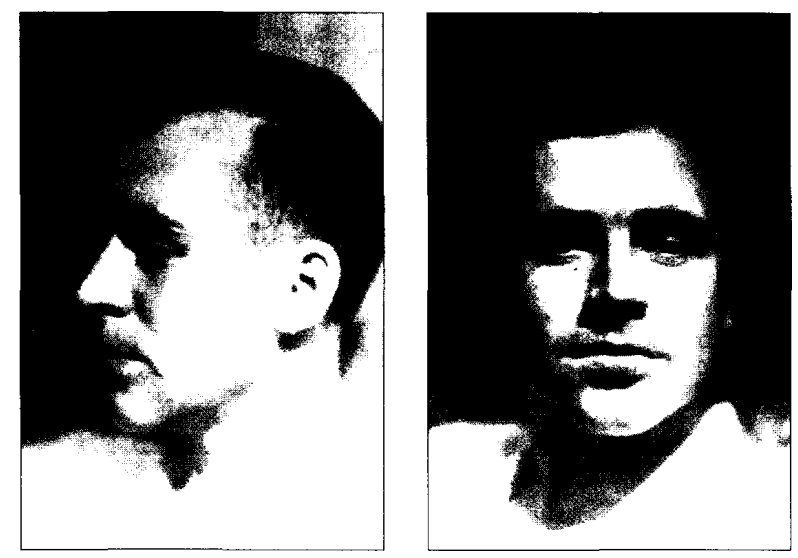
A possibilidade de ancorar a narrativa ficcional em uma narrativa sobre o real ilude o leitor, que pode no texto buscar pistas para o que poderia ter realmente acontecido com Buell Quain. Entretanto, na medida em que se torna linguagem, os critérios de apreensão dos acontecimentos não mais pertencem à ordem do real, mas do ficcional e esses truques tornam-se um ardil para enganar o leitor, como na passagem: "A ficção começou no dia em que botei os pés nos Estados Unidos" (CARVALHO, 2006, p. 142), que sugere não serem os relatos anteriores também ficção.

De acordo com Sophie Beal, nesse romance Bernardo Carvalho cria duas vozes narrativas (o jornalista e Manoel Perna) para destrinchar as incertezas relacionadas com a vida de Quain e a irresolução na tentativa de descortinar sua morte. Por meio disso, "Carvalho's novel underscores the relationship between reality and fiction, the act of constructing a character, and the challenges inherent to narration" $\left(2005\right.$, p. 135) ${ }^{3}$.

Entretanto, pode-se afirmar que talvez não seja somente o objetivo de Carvalho questionar os limites entre ficção e realidade, mas, sim, tornar o relato do real também ficção. O escritor não parece ignorar a força de uma "narrativa de realidade", mas denuncia seu corpo feito de linguagem, cujos significados possuem muito de indefinível. Além disso, a imaginação pode construir o real e não são gratuitas as menções ao medo dos índios Trumai de um imaginário ataque de tribos inimigas, que além de representar o "outro" atemorizador, mostra como o real pode ser construído pelo próprio homem, não sendo a ele anterior.

O discurso indígena, livre de coerções vinculadas à realidade ou à verdade, não está à toa comentado logo no início do romance, como que antecipando a matéria de que este último será feito. Tal como os índios em suas histórias divergentes, o autor nos convida a, além de distinguir real e ficção, jogar com seu texto e a mergulhar na malha de linguagem por ele deliberadamente construída.

Pergunte aos índios. Qualquer coisa. O que primeiro lhe passar pela cabeça. E amanhã, ao acordar, faça de novo a mesma pergunta. E depois de amanhã, mais uma vez. Sempre a mesma pergunta. E a cada dia receberá uma resposta diferente. A verdade está perdida entre todas as contradições e os disparates.

(CARVALHO, 2006, p. 6)

Daí a impossibilidade, em conformidade com Beal (2005), de dar uma versão definitiva dos acontecimentos que cercam a morte de Quain e a inquietude a que é lançado o leitor. Tal como na carta de Marion Quain a Ruth Benedict, "O fato de que nenhum de nós provavelmente jamais conhecerá os fatos torna ainda mais difícil nos desembaraçarmos deles" (CARVALHO, 2006, p. 141).

Na resenha Lobo! Lobo!, Carvalho lamenta o desprestígio da imaginação entre os leitores, que dão preferência a livros pretensamente baseados em "histórias reais", “Como se toda 'obra de imaginação' não estivesse de alguma forma ancorada na

Tradução minha: o romance de Carvalho privilegia o relacionamento entre realidade e ficção, o ato de construir um personagem e os desafios inerentes à narração. 
realidade e não a refletisse. Como se a imaginação não fosse um elemento constitutivo e fundador da realidade, mas um artigo supérfluo" (CARVALHO, 2005, p. 123).

À banalização da arte e "infantilização do espectador", Carvalho propõe formas de arte na qual o significante e a técnica literária emergissem como cernes da sugestão e da imaginação, e não como metáforas simplistas ou manipuladoras do mundo visível. A constante incitação ao "dizer o não dito" nos leva a romper com uma percepção corriqueira ou tradicional do texto literário, segundo a qual a linguagem seria pretexto para a interpretação de seus significados possíveis em sua relação com um contexto material de produção ou com a biografia do autor.

Foucault (2009) percebe esse desconforto em A ordem do discurso, no qual mostra como nossa sociedade busca uma razão lógica para os enunciados, recusando-os na sua desordem. Para esse autor, os discursos não seriam meras representações do mundo, a eles resistentes, mas séries descontínuas de acontecimentos localizados em condições específicas de produção. "Deve-se conceber o discurso como uma violência que fazemos às coisas, como uma prática que lhes impomos em todo o caso; e é nessa prática que os acontecimentos do discurso encontram o princípio de sua regularidade" (FOUCAULT, 2005, p. 53).

Para Foucault (2009), a vontade de verdade (oposição entre o verdadeiro e o falso) é dos princípios de coerção e de exclusão de discursos e se organiza em torno de contingências históricas sempre modificáveis. Essa vontade regeu por muitos séculos nossa vontade de saber e tornou imperativa a exclusão do "falso". Das três formas de exclusão - incluindo a palavra proibida e a interdição da loucura - , a vontade de verdade é a mais abrangente e coercitiva. Entretanto, é dela que menos se fala.

Essa vontade de verdade tende a exercer coerção sobre outros discursos, fazendo que todos eles tenham de se justificar ou fundamentar para serem dados como verdadeiros e, assim, aceitáveis. "Penso na maneira como a literatura ocidental teve de buscar apoio, durante séculos, no natural, no verossímil, na sinceridade, na ciência também - em suma, no discurso verdadeiro" (FOUCAULT, 2005, p. 18).

Em O Sol se põe em São Paulo, Carvalho também desafia o leitor a buscar pistas de real, como os índices topográficos, que sugerem uma pesquisa minuciosa do escritor no Japão. Ainda, é curioso notar a convergência entre um trecho do romance, no qual o narrador entabula conversa com uma senhora japonesa num trem, e a crônica Estranhos num trem, de teor autobiográfico:

Há duas semanas, uma mulher se sentou ao meu lado num trem entre Tóquio e Kyoto. Por alguma razão da qual já não me lembro, começamos a conversar. Conversar é modo de dizer, já que não falo japonês e ela mal compreendia o inglês. É provável que tenha se sentido encorajada ao me ver lendo um clássico da literatura japonesa, o monumental Sasameyuki, de Junichiro Tanizaki (1886 - 1965), que deve sair em breve no Brasil (com o título As irmãs Makioka)

(CARVALHO, 2005, p. 170).

Uma mulher muito branca, com o rosto coberto de pó de arroz e o cabelo grosso preso num arco, sentou-se ao meu lado quando, no dia seguinte, o trem para Tóquio parou por alguns minutos em Nagóia. Meia hora depois, ela continuava a me 
observar com interesse enquanto eu lia a tradução em inglês d'As irmãs Makioka, a obra-prima de Tanizaki [...]. (CARVALHO, 2007, p. 120)

Além do jogo entre real e ficcional, o que sobressai em $O$ Sol se põe em São Paulo é a discussão a respeito da natureza da ficção, na qual coexistem, entre os extremos da verdade e da mentira, a invenção e a experiência. O narrador de SPSP mente a Michiyo/Setsuko ao se declarar um escritor, papel a que ele aspira e que de fato assume a partir da escritura. Paradoxalmente, ao mentir o narrador diz a verdade: "Eu era a pessoa que ela procurava, um mentiroso, alguém que só podia ser o que era não sendo" (CARVALHO, 2007, p. 24).

Outro ilustre "falso mentiroso" é o escritor consagrado Junichiro Tanizaki, cuja casa na narrativa é ambientada próxima ao bosque chamado Tadasu-no-Mori, ou "onde as mentiras se revelam".

Michiyo e o velho escritor se encontraram no bosque, no caminho de terra batida que leva ao templo Shimogano. Ela lhe disse que tudo não passava de um malentendido, que nada daquilo era verdade. E o escritor lhe respondeu: "Só me interessam as mentiras". (CARVALHO, 2007, p. 84)

Entre a verdade e a mentira repousa a ficção de Bernardo Carvalho, num entrecho no qual existe a sombra. O sol poente a que o título de SPSP faz referência é o esplendor causado por uma ilusão - a poluição de São Paulo ou a poeira de Promissão entre a escuridão e luz. A arte de deixar permanecer no indefinido parece ser a ruptura proposta pelo autor em romances nos quais a ênfase recairia não nos significados do enredo quando exaurido em suas metáforas, mas sobre uma discussão a respeito da natureza da linguagem e da literatura como matérias privilegiadas do romance contemporâneo.

\section{Conclusão}

Bernardo Carvalho (2005) propõe o que chama de "literatura de resistência" ao conceber o texto literário como objeto privilegiado de interpretação. Seus romances resistem ao desvendamento e desviam a atenção para os enganos e limites da representação, para a estrutura da narrativa, para os mistérios que cercam a construção de mundos e identidades por meio da escritura.

Por meio de suas propostas, Carvalho luta contra uma literatura fácil de ser apreendida, cuja linguagem nos remeteria à linguagem jornalística; ou contra uma literatura herdeira do realismo, também solicitada pelo mercado editorial como mais vendável. Para ele, um bom romance não reside necessariamente em uma história e em personagens bem construídos ou verossímeis. "Pode ser também um livro sem história, em que os personagens são pretexto para o desenho de uma visão de mundo" (CARVALHO, 2005, p. 27). 
Percebe-se em Carvalho o apelo a uma arte que busque representar o incompreensível e que se recuse a pretextos de entretenimento ou qualquer outra função utilitária. E na queixa da mulher de Tanizaki a Setsuko/Michiyo, em $O$ Sol se Põe em São Paulo, parece surgir um descontentamento do próprio escritor:

Muitos tentaram calá-lo. Teriam feito tudo para que ele deixasse de escrever. Se dependesse deles, ele não teria existido. Se deixar de escrever, eles terão vencido. E não é possível que vençam. Quero dizer: não é possível que vençam sempre. Usaram todos os argumentos para que ele desistisse e desaparecesse. [...] Porque não suportavam ouvi-lo, não era possível que ele existisse, pois os contradizia. (CARVALHO, 2007, p. 79)

Mas essa resistência permite que Carvalho continue à sua maneira a contar suas narrativas de sombra a leitores desconcertados, como nas Nove noites em que Manoel Perna ouve os tresvarios do enigmático Buell Quain.

\section{Referências bibliográficas}

BARTHES, Roland. "A morte do autor". O rumor da língua. São Paulo: Martins Fontes, 2004a, pp. 57-64.

. "Da obra ao texto". O rumor da língua. São Paulo: Martins fontes, 2004b, pp. 65-75.

BEAL, Sophie. "Becoming a character: an analysis of Bernardo Carvalho's Nove Noites". In: Luso-Brazilian Review. Wisconsin: University of Wisconsin Press, vol. 2, n. 42, 2005, pp. 134-149.

BENJAMIN, Walter. "O narrador”. Obras Escolhidas I. $10^{\mathrm{a}}$ ed. São Paulo: Brasiliense, 1996. pp. 197-221.

CARVALHO, Bernardo. Nove noites. São Paulo: Companhia das Letras, 2006. O mundo fora dos eixos. São Paulo: Publifolha, 2005.

Letras, 2007. O sol se põe em São Paulo. São Paulo: Companhia das

FOULCAULT, Michel. A ordem do discurso. 19ª ed. São Paulo: Edições Loyola, 2009. As palavras e as coisas. $5^{\text {a }}$ ed. São Paulo: Martins Fontes, 1990.

GUIMARÃES, Mayara R. "Uma viagem ao inferno do outro: Medo de Sade, de Bernardo Carvalho". In: Revista Crioula, n.3, maio de 2008. Disponível em: < http://www.fflch.usp.br/dlcv/revistas/crioula/edicao/03/Dossie\%20\%20Mayara \%20Ribeiro\%20Guimaraes.pdf>. Acesso em: julho de 2009. 